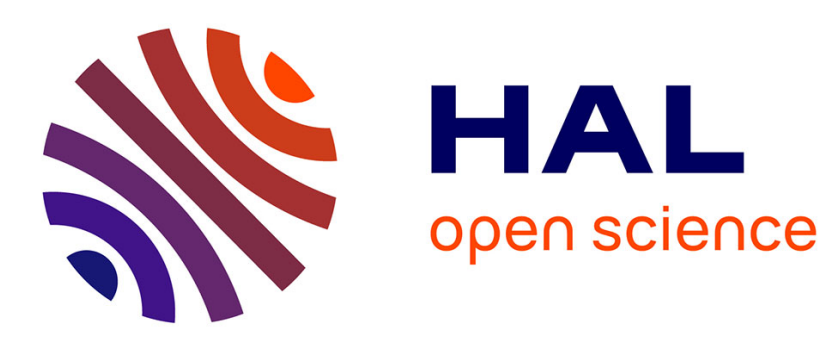

\title{
Is the boreal spring tropical Atlantic variability a precursor of the Equatorial Mode?
}

Marta Martín-Rey, Alban Lazar

\section{To cite this version:}

Marta Martín-Rey, Alban Lazar. Is the boreal spring tropical Atlantic variability a precursor of the Equatorial Mode?. Climate Dynamics, 2019, 10.1007/s00382-019-04851-9 . hal-02171957

\section{HAL Id: hal-02171957 \\ https://hal.science/hal-02171957}

Submitted on 3 Jul 2019

HAL is a multi-disciplinary open access archive for the deposit and dissemination of scientific research documents, whether they are published or not. The documents may come from teaching and research institutions in France or abroad, or from public or private research centers.
L'archive ouverte pluridisciplinaire HAL, est destinée au dépôt et à la diffusion de documents scientifiques de niveau recherche, publiés ou non, émanant des établissements d'enseignement et de recherche français ou étrangers, des laboratoires publics ou privés. 


\title{
Is the boreal spring tropical Atlantic variability
} a precursor of the Equatorial Mode?

\author{
Marta Martín-Rey ${ }^{(1-2)}$ and Alban Lazar ${ }^{(1)}$
}

(1) Laboratoire d'Oceanographie et du Climat: Expérimentation et Approches Numériques (LOCEAN), Université Pierre et Marie Curie (UPMC), Universités Sorbonnes, Paris, France

(2) UMR5318 CECI CNRS-CERFACS, Toulouse, France

Corresponding author current address: Marta Martín del Rey. Departamento de Oceanografía Física y Tecnológica, Instituto de Ciencias del Mar (ICM-CSIC), Passeig Marítim de la Barceloneta, 37-49, 08003 Barcelona (Spain).

Email: mmartin@icm.csic.es; Phone number: +34 932301145

ORCID number: 0000-0001-6234-0447

\begin{abstract}
The Equatorial Mode (EM) governs the tropical Atlantic inter-annual variability during boreal summer. It has profound impacts on the climate of adjacent and remote areas. However, predicting the EM is one of the most challenging and intriguing issues for the scientific community. Recent studies have suggested a possible connection between the boreal spring Meridional Mode (MM) and the EM through ocean wave propagation. Here, we use a set of sensitivity experiments with a medium-resolution ocean model to determine the precursor role of a MM to create equatorial SST variability. Our results demonstrate that boreal summer equatorial SSTs following a MM, are subject to two counteracting effects: the local wind forcing and remotely-excited oceanic waves. For a positive MM, the anomalous easterly winds blowing along the equator, shallow the thermocline, cooling the sea surface via vertical diffusion and meridional advection. Anomalous wind curl excites a downwelling Rossby wave north of equator, which is reflected at the western boundary becoming an equatorial Kelvin wave (KW). This downwelling KW propagates eastward, deepening the thermocline and activating the thermocline feedbacks responsible for the equatorial warming. Moreover, the local wind forcing and RW-reflected mechanism have a significant and comparable impact on the equatorial SST variability. Changes in the intensity and persistence of these distinct forcings will determine the equatorial SST response during boreal summer. Our results give a step forward to the improvement of the EM predictability.
\end{abstract}

Key words: tropical Atlantic, Meridional Mode, Equatorial Mode, ocean waves, SST variability 


\section{Introduction}

The Equatorial Mode (EM) or Atlantic Niño is an air-sea coupled mode that controls the inter-annual tropical Atlantic variability during boreal summer (Zebiak 1993; Lübbecke et al. 2018). During its positive phase, the EM is characterized by an anomalous warming in the eastern equatorial Atlantic, accompanied by a reduction of the climatological trade winds (Lübbecke et al. 2018). The EM is thought to be generated by ocean dynamics (Keenlyside and Latif 2007; Lübbecke and McPhaden 2013; Polo et al. 2015a; Jouanno et al. 2017; Martín-Rey et al. 2019), mainly driven by the Bjerknes feedback (Bjerknes 1969). The Bjerknes mechanism implies the propagation of oceanic waves as a response of an anomalous wind burst in the western equatorial Atlantic (Keenlyside and Latif 2007). Indeed, several authors have underlined the potential role of oceanic waves in the development and decay of the EM (Carton and Huang 1994; Polo et al. 2008a; Lübbecke et al. 2010), shaping its distinct structure and timing (Martín-Rey et al. 2019). In recent decades, additional mechanisms as air-sea fluxes (Nnamchi et al. 2015, 2016), equatorial deep jets (Brandt et al. 2011) or meridional advection of subsurface temperature (Richter et al. 2013) have been also proposed to generate the equatorial SST variability.

The EM has profound impacts on the climate of adjacent and remote areas. Fluctuations in the onset and intensity of West African (Losada et al. 2012a; Rodríguez-Fonseca et al. 2015), Indian (Kucharski et al. 2008; 2009) and East-Asian Monsoon (Jin and Huo 2018) have been found associated with the EM. Moreover, the EM influences the precipitation regime over Europe and Mediterranean Sea (Losada et al. 2012b; Mohino and Losada 2015) and is able to favour the development of a next winter ENSO during certain decades (Rodríguez-Fonseca et al. 2009; Martín-Rey et al. 2014; 2015; Polo et al. 2015b). Thus, predicting the EM is one of the most challenging and intriguing issues for the scientific community.

The EM emerges as an internal mode of tropical Atlantic variability, however, it is also subject to multiple external forcings (Ruiz-Barradas et al. 2000; Czaja et al. 2002), which provide additional sources for its predictability. In this sense, the North Atlantic Oscillation and ENSO phenomenon are the main remote forcings (Latif and Grötzner 2000; Ruiz-Barradas et al. 2000; Handoh et al. 2006). Interestingly, within the tropical Atlantic basin, a possible connection between the boreal spring Meridional Mode (MM) and EM has been suggested (Servain et al. 1999; Murtugudde et al. 2001; Andreoli and Kayano 2003; Foltz and McPhaden 2010a). The MM is characterized by an anomalous inter-hemispheric SST gradient associated with anomalous winds blowing to the warmer hemisphere (Nobre and Shukla 1996). Several mechanisms have been reported to explain the interaction between these modes. Servain et al. (1999) stated that MM and EM can be connected at decadal and short inter-annual time scales, via the latitudinal migration of the Inter Tropical Convergence Zone (Murtugudde et al. 2001; Andreoli and Kayano 2003). The meridional advection of north tropical Atlantic subsurface temperature anomalies (Richter et al. 2013) or the discharge of ocean heat content into the equatorial 
wave guide (Huang and Shukla 1997; Zhu et al. 2012) could also link the tropical and equatorial Atlantic variability.

Remarkably, a dynamical mechanism based on remotely-excited oceanic waves could also mediate the MM-EM connection (Foltz and McPhaden 2010a). During the development of the MM, an anomalous wind stress curl triggers a Rossby wave north of the equator that propagates westward and is reflected at the western boundary. As a consequence, it becomes a Kelvin wave that propagates along the equatorial wave guide, impacting in the equatorial SST anomalies (Foltz and McPhaden 2010b; Burmeister et al. 2016). This wave-reflected mechanism has been considered as part of a destructive interaction between the MM and EM (Foltz and McPhaden 2010a) or as responsible of the inconsistent relationship between ENSO and EM (Lübbecke and McPhaden 2012). However, recent studies highlight the potential role of the wave-reflected mechanism in creating equatorial SST variability during boreal summer (Foltz and McPhaden 2010b; Burmeister et al. 2016). Moreover, Martín-Rey et al. (2019) demonstrate that this ocean wave propagation shapes the distinct structure and timing of the EM. Under this context, disentangling the potential impact of the MM in the development of the Equatorial Mode becomes necessary.

The present study aims to shed light about the precursor role of the MM to generate equatorial Atlantic variability during the following summer. We will determine the mechanisms associated with the development and decay of the MM, with a special focus on the wave activity. Moreover, we will assess the relative contribution of the MMassociated wind forcing and ocean wave propagation in the generation of equatorial SST anomalies, and in turn, of an EM event. For this purpose, a set of sensitivity experiments with the medium-resolution ocean NEMO model have been performed and analysed.

\section{Data and Methodology}

\subsection{Observations model description}

To validate the ability of the model to reproduce the boreal spring tropical Atlantic variability, observed SSTs are considered from the HadISST dataset (Rayner et al. 2003) for the period 1960 to 2011.

The tropical Atlantic configuration of the ocean NEMO model (Madec 2008) has been used (Faye et al. 2015). The horizontal resolution is $14^{\circ}$ with a tripolar grid and $46 \mathrm{z}-$ levels. The model is forced with observed meteorological atmospheric variables (air temperature and air humidity at $2 \mathrm{~m}$, surface wind at $10 \mathrm{~m}$, shortwave and longwave radiation and precipitation) from the DRAKKAR forcing sets, version DFS4.4 (Brodeau et al. 2010). The air-sea fluxes and wind stress are computed interactively using the bulk formula and providing them as outputs by NEMO model. In order to investigate the mechanisms underlying the development of the $\mathrm{MM}$ and its potential connection to the EM, a set of sensitivity experiments have been conducted: 
- INTER: 52-year simulation forced with inter-annual air-sea fluxes for the period 1960-2011 (for more details, see Martín-Rey et al. (2019)).

- MM-REF: 1.5-year simulation forced with the composite air-sea fluxes associated with a typical Meridional Mode event from July (year -1) to December (year 0) (see Methods for more details). This simulation reproduces the growing and decaying phase of the MM pattern, which allows us to assess the impact of the $\mathrm{MM}$ in the following summer equatorial variability.

- MM-WAVE: 1.5-year simulation forced with the composite air-sea fluxes associated with a typical Meridional Mode event from July (year -1) to June (year 0 ). This simulation is similar to MM-REF, but here the atmospheric forcings act only until late spring and they are set to climatological values from July. MMWAVE allows for isolating the contribution of ocean wave propagation in the generation of boreal summer equatorial SST anomalies.

- MM-WIND: 1.5-year simulation forced with the composite air-sea fluxes associated with a typical Meridional Mode event from July (year 0) to December (year 0). The atmospheric forcings have been set to climatological values from July (year -1) to June (year 0). This simulation is similar to MM-REF, but here the atmospheric forcings act only from late spring until winter months. Thus, MM-WIND allows for isolating the role of the local wind forcing to create equatorial SST anomalies during summer months.

The above-mentioned simulations start from the same initial conditions, taken from a stabilized climatological run. The climatological simulation has been run for 10 years using the climatological DFS4.4 forcings from the total period 1958-2011. For the MMWAVE and MM-WIND experiments, a smooth linear transition has been applied to the atmospheric forcings during June, to minimize the initial shock of the model. Our experimental design allows for determining the relative role played by the MM-associated thermodynamic (surface wind) and dynamic processes (oceanic waves) in the development of equatorial SST variability and, in turn, in the generation of a EM event, during next summer.

The output variables used throughout the study are: SST, sea surface height (SSH), the isotherm of $16^{\circ} \mathrm{C}$ as a proxy of the thermocline depth (D16), horizontal currents and wind stress.

\subsection{Methods}

Seasonal anomalies have been computed by subtracting the seasonal cycle of the whole period (1960-2011) for observations and INTER simulation. A high-pass 7-year cut-off Butterworth filter (Butterworth 1930) has been applied to the anomalies to isolate the inter-annual variability and remove the global warming trend. 
177 The leading modes of boreal spring (March-April-May-June) SST variability have been 178 computed using the Principal Component Analysis (PCA, Figure 1a-b). PCA decomposes 179 the anomalous SST space-time field $Y\left(n_{s}, n_{t}\right)$ into a number of modes of variability that 180 maximize its variance. Each mode of variability is formed by a spatial structure 181 (Empirical Orthogonal Function, EOF) and a time series (Principal Component, PC), 182 which explain a fraction of the total variance of the original SST field (von Storch and 183 Zwiers 2001). A typical Meridional Mode has been constructed as a composite of 28 184 events, defined as those years in which the MM time series exceeds \pm 1 std over the whole period 1960-2011 (Figure 1c). The composite of its associated air-sea fluxes is used to force the sensitivity experiments described in Section 2.1.

For the analysis of the MM-REF, MM-WAVE and MM-WIND experiments, the 5-day, monthly and seasonal anomalies are computed by subtracting the associated seasonal cycle from the climatological simulation. To better assess the wave activity, a band-pass Butterworth filter that retains the 60 days - 540 days frequency, has been applied to the 5-day SSH, D16 and wind stress anomalies.

Several climate indices have been defined to characterize the key regions of the MM and EM patterns. North Tropical Atlantic (NTA) index is referred to the averaged anomalous fields in the area $\left[50^{\circ} \mathrm{W}-15^{\circ} \mathrm{W}, 10^{\circ} \mathrm{N}-20^{\circ} \mathrm{N}\right]$, while the equatorial region is characterized by the Atl3 index $\left[20^{\circ} \mathrm{W}-0^{\circ}, 3^{\circ} \mathrm{N}-3^{\circ} \mathrm{S}\right]$.

The calculation of the Ekman velocity has been done according to the following formula:

$$
w_{E}=-\operatorname{curl}(\tau / \rho f)=\partial\left(\tau_{x} / \rho f\right) / \partial y-\partial\left(\tau_{y} / \rho f\right) / \partial x
$$

where $\tau_{\mathrm{x}}$ and $\tau_{\mathrm{y}}$ are the zonal and meridional components of the wind stress, $\rho$ is the sea water density and $\mathrm{f}$ is the Coriolis parameter.

\subsection{Heat budget analysis}

To explore the air-sea interactions responsible for the development and decay of the MM, a heat budget analysis has been carried out in the tropical Atlantic. Our model allows the interactive calculation of the heat budget in the mixed layer using the bulk formula. The different terms of equation [1] are provided as outputs by the model. The temporal variations of the mixed layer temperature are explained by the contribution of diverse terms (Peter et al. 2006; Martín-Rey et al. 2019):

$$
\partial_{t}\langle T\rangle=-\left\langle u \partial_{x} T\right\rangle-\left\langle v \partial_{y} T\right\rangle+\left\langle D_{l}(T)\right\rangle-\frac{1}{h} \frac{\partial h}{\partial t}\left(\langle T\rangle-T_{z=-h}\right)-\left\langle w \partial_{z} T\right\rangle-\frac{1}{h}\left(\kappa_{z} \partial_{z} T\right)_{z=-h}+\frac{Q_{s}\left(1-F_{z=-h}\right)+Q^{*}}{\rho_{0} C_{p} h}
$$


with $\langle *\rangle=\frac{1}{h} \int_{-h}^{0} * d z$ where $h$ is the depth of the mixed layer; $T$ and $T_{h}$ are the temperature of the mixed layer and below the mixed layer respectively; $u, v$ and $w$ are the zonal, meridional and vertical currents, respectively; $D_{l}$ is the lateral diffusion operator and $\kappa_{z}$ is vertical mixing coefficient. Notice that the net surface heat fluxes, $Q_{n e t}$, is decomposed into the non-solar (latent, sensible and longwave) $Q^{*}$ and solar (shortwave) $Q_{s}$ heat fluxes. As not all the incident shortwave solar radiation will penetrate in the mixed layer, the function $F_{z=-h}$ is included, which describes the fraction of shortwave fluxes absorbed in this layer and thus contributing to the mixed layer heating. Finally, $\rho_{0}$ is the seawater density and $C_{p}$ is the seawater specific heat capacity coefficient.

The equation [1] shows that the tendency of the temperature in the mixed layer (left) can be expressed as the sum of atmospheric and oceanic contributions. The atmospheric term is referred to air-sea fluxes (c), while the oceanic component is associated with horizontal terms (a, zonal and meridional advection and lateral diffusion) and vertical processes (b, turbulent mixing, vertical advection and entrainment). This approach has been found to be a very useful method to investigate the air-sea interactions involved in the tropical Atlantic variability modes (Polo et al. 2015a; Martín-Rey et al. 2019).

\section{Results}

\subsection{Tropical Atlantic inter-annual variability in boreal spring}

The Meridional Mode (MM) emerges as the second mode of tropical Atlantic SST variability during boreal spring in both observations and INTER simulation for the period 1960-2011 (Figure 1a-b). It accounts for the $24.6 \%$ and $24.8 \%$ of the total variance in observations and model simulation respectively. The inter-hemispheric SST gradient is well captured by the model $(\mathrm{r}=0.96)$, although the equatorial cooling displays a westward extension reaching South American coast compared to the observations (Figure 1a-b). This can be due to the equatorial cold bias of the model, associated with a thinner equatorial mixed layer and reduced thermocline slope (Martín-Rey et al. 2019). The interannual variability of the MM is also well reproduced by the INTER simulation over the whole period $(\mathrm{r}=0.9$, Figure $1 \mathrm{c})$.

As a first attempt to evaluate the possible connection between MM and EM, lead-lag correlation between the time series (PC2 fixed in MAMJ) of the MM and Atl3 SST index from JFMA to DJFM has been computed (Figure 1d). Significant negative correlations are found from previous winter to next summer, being maximum at lag 0 (MAMJ, up to 0.8). Our results show that the entire evolution of the MM is strongly linked to equatorial SST anomalies. In particular, the correlation between MM and boreal summer (JJAS) Atl3 index reaches $0.4-0.5$, which suggests that the MM would explain around $20 \%$ of the summer equatorial SST variability and thus an important contribution to the generation of the EM (Figure 1d). 
To gain further understanding of the physical processes controlling the development of the MM and its potential link to the EM, a sensitivity experiment based on a typical MM pattern has been performed, hereinafter MM-REF (see section 2.2). This typical MM has been computed as a composite MM SST pattern, which has a good agreement (not shown) with the leading mode of boreal spring variability from INTER simulation (Figure 1b). MM-REF reveals that the development of the MM starts in boreal winter (JFM) with a reduction of the north-easterly trades, associated with an anomalous cyclonic circulation (Figure 2a). These anomalous winds persist until late spring (Figure 2b), decreasing the latent heat loss and warming the mixed layer (Figure 2d). In contrast, the trades intensify in the south tropical Atlantic from boreal winter to spring (Figure 2a-b), enhancing the evaporation and cooling the sea surface (not shown). Our results corroborate the role of the air-sea fluxes to lead the large-scale structure of the MM, with a negligible contribution of oceanic terms (Amaya et al. 2016; Chang et al. 1997, Wagner et al. 1996; Carton et al. 1996).

This asymmetric SST structure causes a meridional sea surface pressure gradient (not shown), according with the Wind-Evaporation-SST feedback (Amaya et al. 2016), given rise to anomalous cross-equatorial winds blowing to the warmer hemisphere (Figure 2ac). Consequently, the easterlies are reinforced along the equator from winter to spring, shallowing the thermocline and activating the ocean processes responsible for the surface cooling (Figure 2a-c,e). During summer months, the MM-wind forcing decays and the equatorial band warms up, due to vertical diffusion and meridional advection respectively (Figure 2d-e). Notice that during the entire MM evolution, the air-sea fluxes tend to damp the equatorial SST anomalies (blue line, Figure 2e). Thus, our results provide further evidence of the essential role of ocean dynamics to control the equatorial SST variations (Foltz et al. 2003; Peter et al. 2006; Polo et al. 2015a; Martín-Rey et al. 2019).

\subsection{Wave propagation in the MM evolution}

During the development of the MM event, the atmospheric wind forcing originates an anomalous zonal SSH gradient at the equator (shaded, Figure 3a). This east-west SSH dipole shifts its phase during summer months (shaded, Figure 3b), resembling the Kelvin and Rossby wave signature of the delayed oscillator mechanism (Suarez and Schopf 1988). This anomalous configuration suggests the existence of ocean wave activity during the development and decay of the MM, according to previous findings (Foltz and McPhaden 2010a; Burmeister et al. 2016). However, a better characterization of the ocean wave propagation, as well as the mechanisms responsible of the excitation of Rossby and Kelvin waves, is required.

Figure 3a reveals that an anomalous anticyclonic circulation produces a negative wind (positive Ekman velocity, black contours) and downwelling conditions around $30^{\circ} \mathrm{W}$ - 
$20^{\circ} \mathrm{W}$ from January to June (white box). This vertical Ekman velocity (dark grey line, Figure $3 \mathrm{c}$ ) is produced by an anomalous convergence of horizontal currents (purple line), which causes the SSH to rise (orange line) and the thermocline to deepen from January to May (magenta line, Figure 3c). The simultaneous alteration of off-equatorial surface and subsurface suggests the excitation of a baroclinic ocean wave. To better visualize the wave activity during the MM, time-longitude diagrams of filtered 5-day SSH anomalies at $2^{\circ} \mathrm{N}-4^{\circ} \mathrm{N}$ and along the equator are displayed in Figure 4.

During the growing phase of the $\mathrm{MM}$, an anomalous wind burst in the western equatorial Atlantic $\left[40^{\circ} \mathrm{W}-30^{\circ} \mathrm{W}\right]$, triggers a set of upwelling Kelvin waves, uKW1 and uKW2 (pink arrows), propagating eastward from February to May and May to July respectively (Figure $4 \mathrm{~b})$. The uKW1 and $\mathrm{uKW} 2$ resemble $2^{\text {nd }}$ baroclinic modes $(1.27 \mathrm{~m} / \mathrm{s}$ and 1.45 $\mathrm{m} / \mathrm{s}$ respectively; Illig et al. (2004); Polo et al. (2008b)) that shallow the thermocline and favour the mixed layer cooling by vertical processes from February to July (Figure 2e). Notice that $\mathrm{uKW} 1$ is reflected at the African coast, returning as an upwelling Rossby wave (uRW1, $0.59 \mathrm{~m} / \mathrm{s}, 2^{\text {nd }}$ baroclinic mode) along $2^{\circ} \mathrm{N}-4^{\circ} \mathrm{N}$ (pink arrow, Figure $4 \mathrm{c}$ ).

During the decaying phase of the MM, a downwelling Rossby wave (dRW) is excited north of the equator (Figure 4a), associated with an anomalous negative wind stress curl (Figure $3 \mathrm{c})$. The dRW propagates to the west as a $2^{\text {nd }}$ baroclinic mode $(\sim 0.56 \mathrm{~m} / \mathrm{s})$ and is reflected at the western boundary in June-July (Figure $4 \mathrm{a}$ ), becoming an equatorial downwelling Kelvin wave ( $\mathrm{dKW} \sim 1.4 \mathrm{~m} / \mathrm{s}$, Figure $4 \mathrm{~b})$. From July to September, as the $\mathrm{dKW}$ propagates eastward, the thermocline deepens setting up the favourable conditions to warm the equator by vertical diffusion and meridional advection (Figure 2e).

Our results confirm the existence of RW-reflected mechanism during the MM evolution proposed by previous studies (Foltz and McPhaden 2010a). Furthermore, we demonstrate that oceanic waves modulate the development and decay of the Meridional Mode. Locally-excited equatorial Kelvin waves contribute to generate the MM-associated equatorial cold tongue, while remotely-excited Rossby wave tends to counteract these equatorial SSTs during summer months. This is in agreement with Martín-Rey et al. (2019) who suggested the crucial role of oceanic waves in shaping the distinct structure and timing of the EM. Nevertheless, it is worth mentioning that we can interpret our results as a two-way contribution of the MM to the equatorial SST anomalies during boreal summer. On the one hand, local easterly winds produce a shallower equatorial thermocline, favouring the surface cooling via vertical diffusion. On the other hand, the north-equatorial wind curl triggers a downwelling RW boundary-reflected into a KW that deepens the thermocline and sets up the favourable conditions to warm the equator. The competition between both phenomena will determine the equatorial SST anomalies during boreal summer, and thus, the potential relation between the MM and EM.

Under this context, a quantification of the relative contribution of the oceanic waves, compared to the local wind forcing on the equatorial SST variability is necessary and will be assessed in next section. 


\subsection{Impact of the MM-associated ocean wave and wind forcing in the equatorial Atlantic variability}

354

355

356

357

358

359

360

361

362

363

364

365

366

367

368

369

370

371

372

373

374

375

376

377

378

379

380

381

382

383

384

385

386

387

388

389

390

391

392

393

394

The boreal summer equatorial SST anomalies following the peak of the MM are subject to two distinct contributions: the local wind forcing and the remotely-forced ocean waves. To isolate the relative contribution of each forcing, two additional sensitivity experiments have been performed, MM-WAVE and MM-WIND (for more details, see Section 2.2). In the MM-WAVE, the atmospheric forcing is suppressed from June, allowing the free propagation of the RW-reflected into the equatorial dKW (Figure 4) during summer months. Complementary, MM-WIND experiment only considers the atmospheric forcing from June, which allows for determining the impact of the local wind in the generation of equatorial SST variability.

Figure 5 presents the summer (August) SST anomalies in the equatorial Atlantic for the three sensitivity experiments. MM-WAVE and MM-WIND clearly illustrates a different and opposite impact over the equatorial SSTs. While MM-WAVE shows a strong equatorial warming in August (up to $0.5^{\circ} \mathrm{C}$ ), MM-WIND presents a homogeneous surface cooling $\left(\sim 0.2^{\circ}-0.3^{\circ} \mathrm{C}\right)$. The temporal evolution of the 5-day SST and SSH anomalies in the Atl 3 region reveals that the equatorial band warms up two times faster in MM-WAVE respect to MM-REF $\left(0.165^{\circ} \mathrm{C} / \mathrm{month}\right.$ vs $0.062^{\circ} \mathrm{C} / \mathrm{month}$, Figure $\left.5 \mathrm{c}\right)$, associated with the early arrival of the dRW at the eastern equatorial Atlantic (thin pink line, Figure $5 \mathrm{c}$ ). Indeed, the $\mathrm{dKW}$ propagation is more than two time faster in absence of local wind $(\sim 3.4$ $\mathrm{m} / \mathrm{s}$ in MM-WAVE respect to $1.4 \mathrm{~m} / \mathrm{s}$ in MM-REF). In MM-REF, the anomalous easterlies blow against the wave propagation, establishing a competitive interaction between both effects (thin purple line, Figure 5a). When the intensified equatorial winds act alone during summer months, they are able to create an equatorial cooling up to $0.2^{\circ} \mathrm{C}$ (orange line, Figure 5a).

This competition between the surface winds and ocean waves is clearly illustrated in the heat budget analysis of the eastern equatorial Atlantic (Figure 6). In absence of wind forcing, the propagation of the $\mathrm{dKW}$ deepen the thermocline, enhancing the contribution of vertical processes (dark green line) responsible to warm the equator from July to midAugust (dark blue line, Figure 6b). The horizontal terms has a negligible effect, while the air-sea fluxes tend to damp the equatorial warming (light green and blue lines, Figure 6b). In contrast, when both the atmospheric forcing is included, the positive temperature trend exhibits large variations (dark blue line, Figure 6a) due to the dominant effect of horizontal advection (light green line, Figure 6a) added to the air-sea fluxes (light blue line, Figure 6c). Both phenomena tend to counteract the impact of the ocean dynamics activated by the dKW propagation (dark green line, Figure $6 a$ ).

Our results bring to light the competition between two distinct forcings to create the equatorial Atlantic variability during a MM event. Both, the MM-associated local surface wind and remotely-excited oceanic waves control equatorial SST anomalies during next 
summer. We have demonstrated for the first time that oceanic waves and wind forcing have a significant and comparable impact in the generation of equatorial SST variability (up to $0.2^{\circ} \mathrm{C}$, Figure 5a), strong enough to generate an EM event during boreal summer.

It is worth-mentioning that our results are referred to a typical MM event in which the local wind counteracts the ocean wave contribution, given rise to with quasi-neutral equatorial SST conditions during boreal summer (Figure 2c and Figure 5a). However, changes in the amplitude or persistence of the atmospheric and/or oceanic forcing could modify the boreal summer equatorial SST response.

\section{Discussion and conclusions}

We have investigated the precursor role of the Meridional Mode in generating equatorial Atlantic variability and potentially an Equatorial Mode event during next summer. For this purpose, we have performed a set of sensitivity experiments with the ocean NEMO model. The main conclusions achieved in the present study are:

- The model reproduces quite well the spatial structure and inter-annual variability of the Meridional Mode (MM). The MM shows a strong connection with the equatorial SST anomalies during its entire evolution.

- The inter-hemispheric SST gradient of the MM pattern is driven by thermodynamic processes (air-sea fluxes), while equatorial SST anomalies are controlled by ocean dynamics (vertical diffusion and horizontal advection).

- Oceanic waves contribute actively to the development and decay of the MM, shaping the equatorial SST anomalies:

○ During the growing phase of the MM: anomalous wind burst in the western equatorial Atlantic trigger a set of upwelling Kelvin waves (KW) that propagate eastward during winter and spring, shallowing the thermocline and favoring the equatorial cooling via vertical diffusion and meridional advection.

- During the decaying phase of the MM: an anomalous negative wind stress curl north of the equator, originates an anomalous convergence of surface currents and an Ekman pumping during boreal spring. Consequently, the SSH elevates and the thermocline deepens, exciting a downwelling Rossby wave that is reflected in the western boundary, becoming an equatorial $\mathrm{dKW}$ in boreal summer. The $\mathrm{dKW}$ deepens the thermocline, activating the vertical processes responsible to warm up the equator. 
- Two distinct forcings are responsible of the boreal summer equatorial SSTs following a MM event: the local surface wind and the remotelyexcited oceanic waves. Both contributions show a significant and comparable effect over the equatorial Atlantic SST variability. In absence of local wind forcing, the equatorial band warms up two times faster due to the early arrival of the $\mathrm{dKW}$ that activates the vertical processes. However, the surface wind contribution shallows the equatorial thermocline, favouring the surface cooling and counteracting the oceanic wave effect.

In the present paper, we provide further evidence of the precursor role of the MM to generate an EM during next summer. The equatorial SST variability is subject to two distinct and competitive contributions that determine the equatorial SST response during boreal summer. Remarkably, Figure 7 illustrates that there are some MM events followed by the same-sign EM. The Meridional Mode event of 1966 was followed by a strong equatorial warming, a positive Equatorial Mode-like pattern (Figure 7b-c). Similarly, for the negative MM event of 2009 (Figure 7d-e). According to our results, during those MM events, the reflected-RW mechanism was stronger than the local wind, being able to transfer the north tropical SST anomalies to the equatorial band (Burmeister et al. 2016). Thus, changes in the amplitude and strength of the MM-associated surface wind could modulate the equatorial SSTs during next summer, and then the MM-EM connection.

Our results give a step forward in the better understanding of the processes controlling the Meridional Mode and its connection to the equatorial Atlantic variability. Moreover, this study provides evidence about the precursor role of the Meridional Mode to generate an Equatorial Mode event during next summer, which could be very useful to improve the predictability of the EM. Nevertheless, further research is still required to better understand the interaction between the MM and EM, conciliating the distinct proposed mechanisms as well as the possible multidecadal modulation by natural variability and Global Warming.

Acknowledgements: The research leading to these results received funding from the EU FP7/2007-2013 under Grant Agreement 603521 (PREFACE project), the MORDICUS grant under contract ANR-13-SENV-0002-01, CNES/EUMETSAT (CNES - DIA/TEC2016.8595, EUM/LEO-JAS3/DOC/16/852054) and the MSCA-IF-EF-ST FESTIVAL (H2020-EU project 797236). The observed SSTs from HadISST dataset were provided by the MetOffice Hadley Centre, from its website at https://www.metoffice.gov.uk/hadobs/hadisst/. The data from the INTER, MM-REF, MM-WIND and MM-WAVE simulations are available from the authors upon request. 
Figure 1. Observed and simulated Meridional Mode and its connection with equatorial SST variability. (a-b) Regression maps of the anomalous SSTs (in ${ }^{\circ} \mathrm{C}$ ) on the Principal Component (PC) of the second mode (EOF2) of inter-annual tropical Atlantic variability in boreal spring (March-April-May-June) for the period 1960-2011 from observations and INTER simulation. (c) Principal components of the observed (solid orange line) and modelled (dashed pink line) Meridional Mode for the period 1960-2011. Grey lines denote the \pm 0.5 std threshold. (d) Lead-lag correlation between the 4-month averaged SST anomalies in the At 13 region $\left[20^{\circ} \mathrm{W}-0^{\circ}, 3^{\circ} \mathrm{N}-3^{\circ} \mathrm{S}\right]$ and the Meridional Mode (PC2 of TA SST in MAMJ) for observations (pink dots) and INTER (green dots) during the period 1960-2011. The PC2 of the Meridional Mode is fixed in MAMJ (Lag 0), thus, negative lags (from JFMA to MAMJ) indicate At13 leading while positive lags (from MAMJ to DJFM) imply the leadership of Meridional Mode over the equatorial SST anomalies. Statistically significant scores at $95 \%$ confidence level according to a t-test are shown in filled dots.

Figure 2. Air-sea interactions underlying the development of the Meridional Mode. (a-c) Anomalous simulated SSTs (shaded, in ${ }^{\circ} \mathrm{C}$ ) and observed surface wind forcing (vectors, in $\mathrm{m} / \mathrm{s}$ ) from boreal winter (DJF), spring (MAM) and summer months (JJA) for the MM-REF simulation. Composite surface winds used to force MM-REF come from DFS4.4 dataset. (d-e) Temporal evolution of the heat budget terms in North Tropical Atlantic, NTA $\left[50^{\circ} \mathrm{W}-15^{\circ} \mathrm{W}, 5^{\circ} \mathrm{N}-20^{\circ} \mathrm{N}\right]$ and At $3\left[20^{\circ} \mathrm{W}-0^{\circ}, 3^{\circ} \mathrm{N}-3^{\circ} \mathrm{S}\right]$ regions (green boxes in (c)) from previous fall (year -1) to winter months (year 0) following the Meridional Mode. The heat budget terms displayed are the tendency of the mixed layer temperature (purple line), the air-sea fluxes (blue line) and oceanic horizontal (green line) and vertical processes (red line). The data comes from MM-REF simulation.

Figure 3. Excitation of ocean waves during the development of the Meridional Mode. (a-b) Anomalous temporal variations of SSH (shaded, in $\mathrm{m}$ ), wind stress (purple vectors, in $\mathrm{N} / \mathrm{m}^{2}$ ) and vertical Ekman velocity (black contours, $\mathrm{m} / \mathrm{s}$ ) for boreal winter-spring (January-May, a) and summer months (July-September, b) from MM-REF simulation. (c) Seasonal evolution of monthly variations of SSH (solid orange line, in cm/day), D16 (solid pink line, in m), Ekman vertical velocity (solid black line, in m/day) and divergence of the horizontal currents (solid purple line in $\mathrm{m} 3 /$ day) averaged $\left[30^{\circ} \mathrm{W}-20^{\circ} \mathrm{W}, 3^{\circ} \mathrm{N}-6^{\circ} \mathrm{N}\right]$ (white box in (a)). The monthly variations are computed as the difference between the last 5-day mean data respect to the first 5-day mean data of each month.

\section{Figure 4. Equatorial wave propagation associated with the Meridional Mode.}

Time-longitude diagrams of anomalous filtered 5-days SSH anomalies (in $\mathrm{cm}$ ) at $2^{\circ} \mathrm{N}$ $4^{\circ} \mathrm{N}(\mathrm{a}, \mathrm{c})$ and along the equator $(\mathrm{b})$. Notice that the $2^{\circ} \mathrm{N}-4^{\circ} \mathrm{N}$ diagram has been duplicated and the $\mathrm{x}$-axis is reversed to better visualize the propagation and coastal-boundary reflection of the Rossby and Kelvin waves along the equatorial Atlantic. The propagation 
521 of Kelvin and Rossby waves are highlighted with white and pinks arrows, for

522 downwelling and upwelling conditions respectively.

523

524 Figure 5. Impact of the wave activity in the equatorial Atlantic variability. (a-c)

525 Anomalous SST(shaded, in ${ }^{\circ} \mathrm{C}$ ) and surface wind forcing (vector, in $\mathrm{m} / \mathrm{s}$ ) in the equatorial

526 Atlantic in August for MM-REF, MM-WAVE and MM-WIND. (d-e) Time series of

527 anomalous 5-day SST (solid thick lines, in ${ }^{\circ} \mathrm{C}$ ) and SSH (solid thin lines, in $\mathrm{cm}$ ) in the

528 Atl3 region for MM-REF, MM-WAVE and MM-WIND from January to December.

529

530 Figure 6. Heat budget analysis in the eastern equatorial Atlantic. (a-c) Anomalous 5-

531 day heat budget terms (temperature trend, air-sea fluxes, vertical and horizontal

532 processes, in ${ }^{\circ} \mathrm{C} /$ day) in MM-REF, MM-WAVE and MM-WIND simulations from

533 January to December.

534

535 Figure 7. Meridional Mode followed by Equatorial Mode events. (a) Time series of

536 Meridional Mode (PC2) and Equatorial Mode (At13) during 1960-2011 for observations

537 and INTER simulation. (b-e) Observed anomalous tropical Atlantic SSTs in boreal spring

538 (MAMJ) and summer (JJAS) months are displayed for two Meridional Mode events,

5391966 and 2009. In both cases, pronounced equatorial SST anomalies during summer

540 months followed the development of a same-sign Meridional Mode event. 
(a) EOF2 SST MAMJ OBS

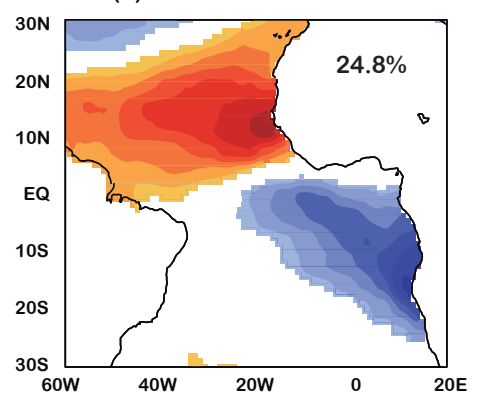

(b) EOF2 SST MAMJ NEMO

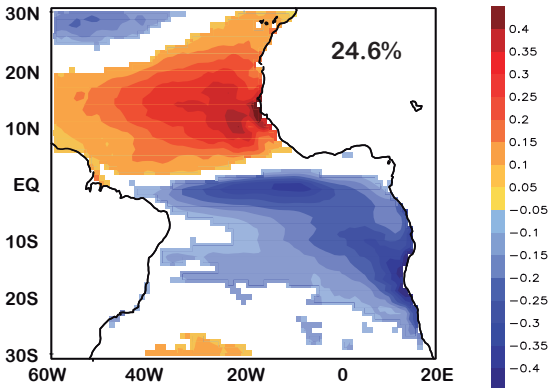

(c) PC2 TA SST MAMJ OBS \& NEMO 1960-2011

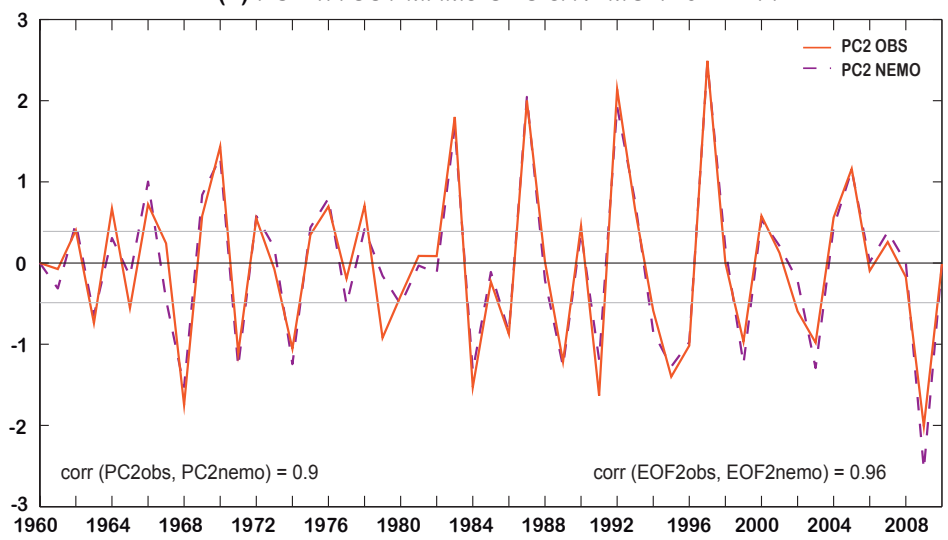

(d) Lead-lag corr MM - Atl3 SST 1960-2011

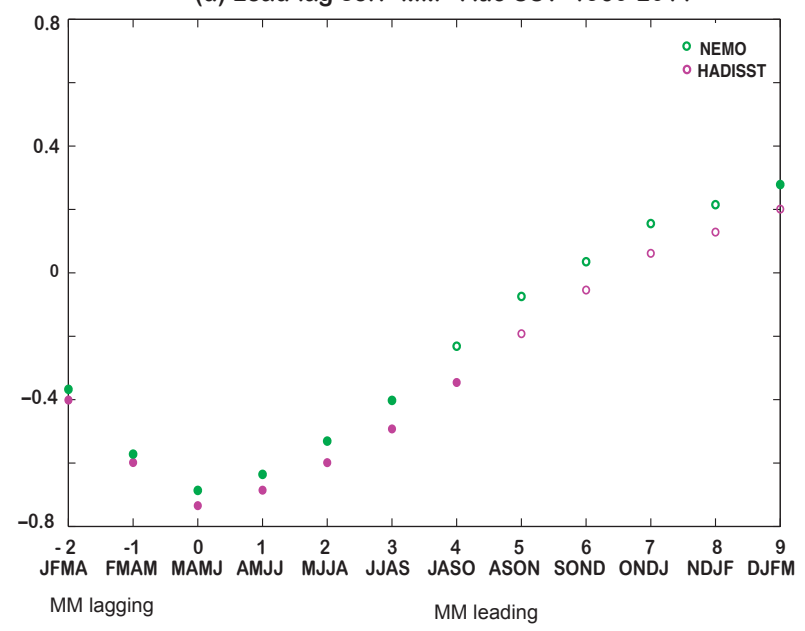

Figure 1. Observed and simulated Meridional Mode and its connection with equatorial SST variability. (a-b) Regression maps of the anomalous SSTs (in ${ }^{\circ} \mathrm{C}$ ) on the Principal Component (PC) of the second mode (EOF2) of inter-annual tropical Atlantic variability in boreal spring (March-April-May-June) for the period 1960-2011 from observations and INTER simulation. (c) Principal components of the observed (solid orange line) and modelled (dashed pink line) Meridional Mode for the period 1960-2011. Grey lines denote the \pm 0.5 std threshold. (d) Lead-lag correlation between the 4-month averaged SST anomalies in the Atl 3 region $\left[20^{\circ} \mathrm{W}-0^{\circ}, 3^{\circ} \mathrm{N}-3^{\circ} \mathrm{S}\right]$ and the Meridional Mode (PC2 of TA SST in MAMJ) for observations (pink dots) and INTER (green dots) during the period 1960-2011. The PC2 of the Meridional Mode is fixed in MAMJ (Lag 0), thus, negative lags (from JFMA to MAMJ) indicate Atl3 leading while positive lags (from MAMJ to DJFM) imply the leadership of Meridional Mode over the equatorial SST anomalies. Statistically significant scores at $95 \%$ confidence level according to a t-test are shown in filled dots 
(a) SST-WIND JFM MM-REF

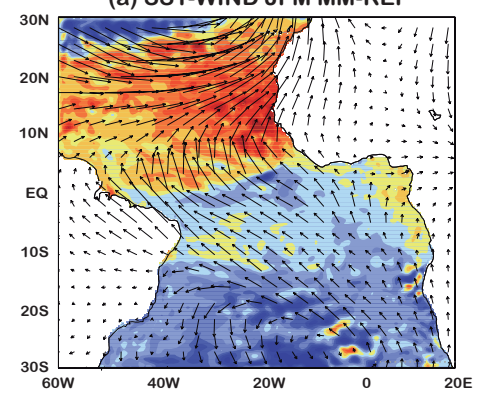

(b) SST-WIND MAM MM-REF

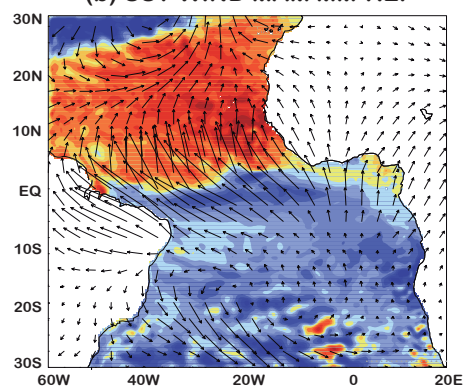

(c) SST-WIND JJA MM-REF

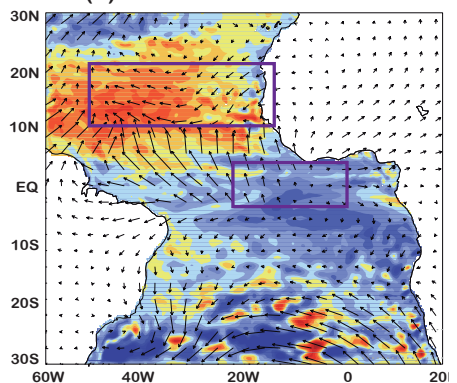

(d) HB NTA $\left[50^{\circ} \mathrm{W}-15^{\circ} \mathrm{W}, 10^{\circ} \mathrm{N}-20^{\circ} \mathrm{N}\right] \quad M M-R E F$

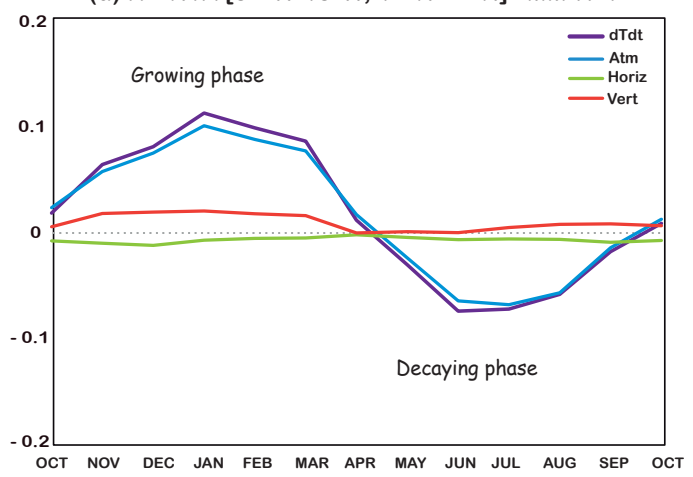

(e) HB ATL3 $\left[20^{\circ} \mathrm{W}-0^{\circ}, 3^{\circ} \mathrm{S}-3^{\circ} \mathrm{N}\right] \quad \mathrm{MM}-\mathrm{REF}$

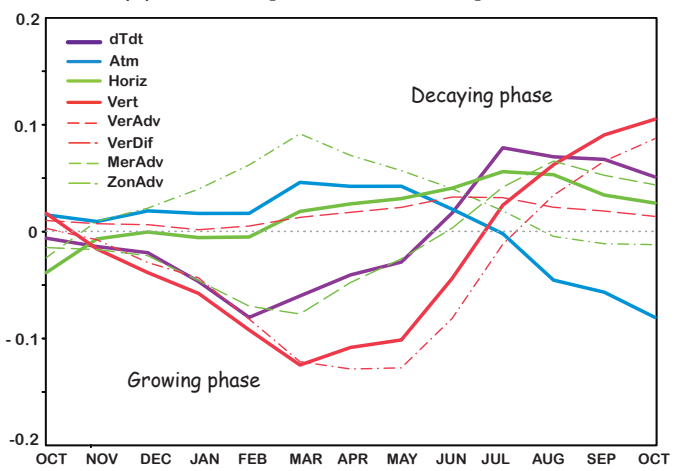

Figure 2. Air-sea interactions underlying the development of the Meridional Mode. (a-c) Anomalous simulated SSTs (shaded, in ${ }^{\circ} \mathrm{C}$ ) and observed surface wind forcing (vectors, in $\mathrm{m} / \mathrm{s}$ ) from boreal winter (DJF), spring (MAM) and summer months (JJA) for the MM-REF simulation. Composite surface winds used to force MM-REF come from DFS4.4 dataset. (d-e) Temporal evolution of the heat budget terms in North Tropical Atlantic, NTA $\left[50^{\circ} \mathrm{W}-15^{\circ} \mathrm{W}, 5^{\circ} \mathrm{N}-20^{\circ} \mathrm{N}\right]$ and At $13\left[20^{\circ} \mathrm{W}-0^{\circ}, 3^{\circ} \mathrm{N}-3^{\circ} \mathrm{S}\right]$ regions (green boxes in (c)) from previous fall (year -1) to winter months (year 0) following the Meridional Mode. The heat budget terms displayed are the tendency of the mixed layer temperature (purple line), the air-sea fluxes (blue line) and oceanic horizontal (green line) and vertical processes (red line). The data comes from MM-REF simulation. 
(a) DifSSH Wekm windstress Jan-May MM-REF

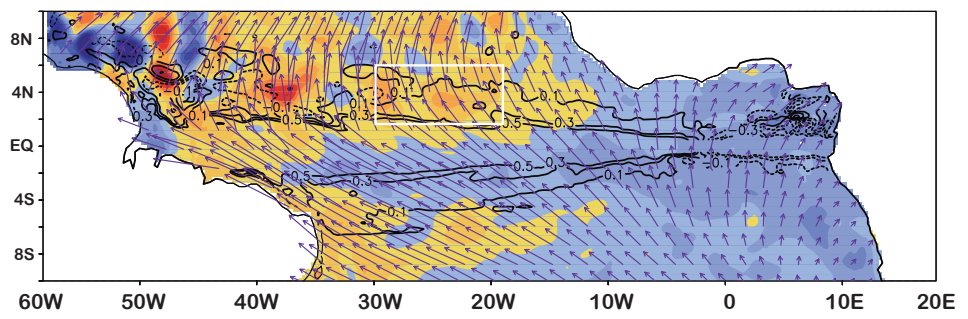

(b) DifSSH Wekm windstress Jul-Sep MM-REF

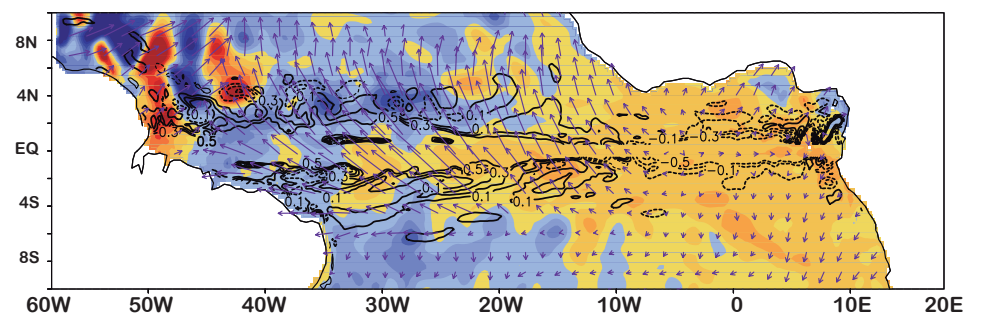

$\begin{array}{llllllllll}-0.06-0.05-0.04-0.03-0.02-0.01 & 0 & 0.01 & 0.02 & 0.03 & 0.04 & 0.05 & 0.06 & 0.007\end{array}$

(c) SSH-D16-EKMAN-CURRENTS $30^{\circ} \mathrm{W}-20^{\circ} \mathrm{W} 3^{\circ} \mathrm{N}-6^{\circ} \mathrm{N}$

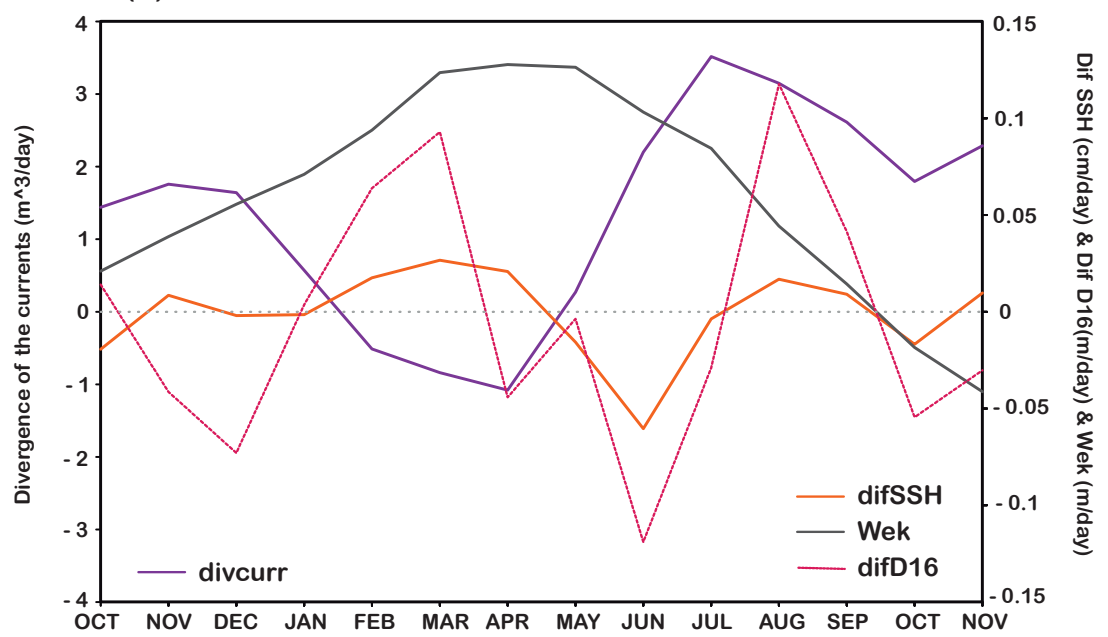

Figure 3. Excitation of ocean waves during the development of the Meridional Mode.

(a-b) Anomalous temporal variations of SSH (shaded, in m), wind stress (purple vectors, in N/ $\mathrm{m}^{2}$ ) and vertical Ekman velocity (black contours, $\mathrm{m} / \mathrm{s}$ ) for boreal winter-spring (January-May, a) and summer months (July-September, b) from MM-REF simulation. (c) Seasonal evolution of monthly variations of SSH (solid orange line, in cm/day), D16 (solid pink line, in m), Ekman vertical velocity (solid black line, in $\mathrm{m} /$ day) and divergence of the horizontal currents (solid purple line in $\mathrm{m} 3 /$ day) averaged $\left[30^{\circ} \mathrm{W}-20^{\circ} \mathrm{W}\right.$, $3^{\circ} \mathrm{N}-6^{\circ} \mathrm{N}$ ] (white box in (a)). The monthly variations are computed as the difference between the last 5 day mean data respect to the first 5-day mean data of each month 
(a) SSH-WINDSTRESS $5 \mathrm{~d}$ anom $2^{\circ} \mathrm{N}-4^{\circ} \mathrm{N}$

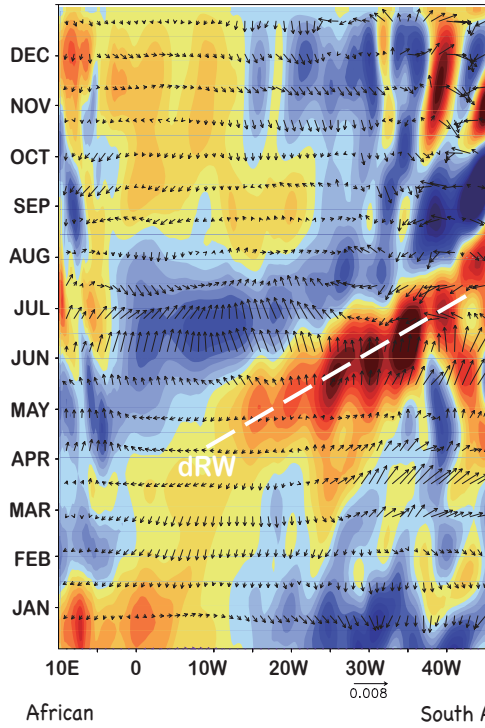

African

coast (b) SSH-USTRESS $5 \mathrm{~d}$ anom EQ

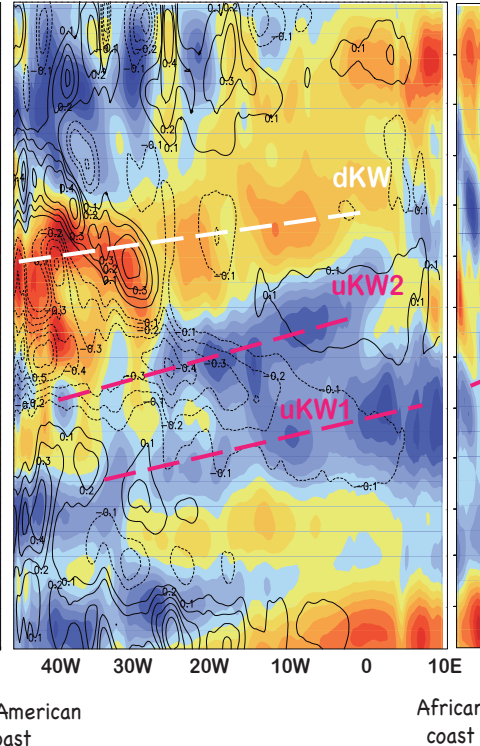

(c) SSH 5 d anom $2^{\circ} \mathrm{N}-4^{\circ} \mathrm{N}$

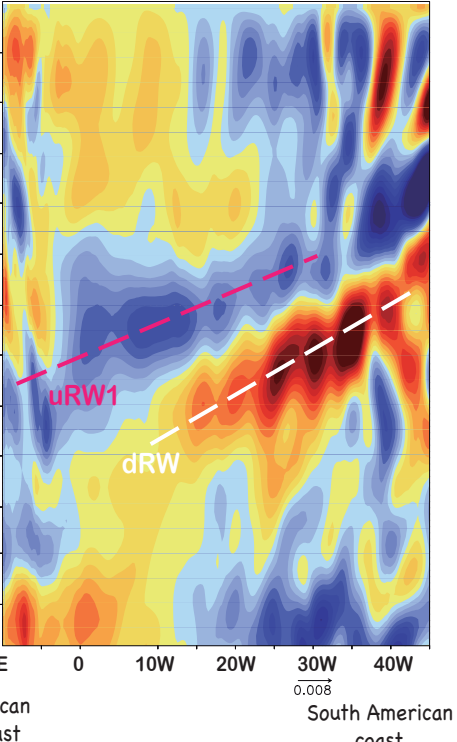

$\begin{array}{lllllllllll}-2 & -1.6 & -1.2 & -0.8 & -0.4 & 0 & 0.4 & 0.8 & 1.2 & 1.6 & 2\end{array}$

Figure 4. Equatorial wave propagation associated with the Meridional Mode.

Time-longitude diagrams of anomalous filtered 5-days SSH anomalies (in $\mathrm{cm}$ ) at $2^{\circ} \mathrm{N}-4^{\circ} \mathrm{N}(\mathrm{a}, \mathrm{c}$ ) and along the equator (b). Notice that the $2^{\circ} \mathrm{N}-4^{\circ} \mathrm{N}$ diagram has been duplicated and the $\mathrm{x}$-axis is reversed to better visualize the propagation and coastal-boundary reflection of the Rossby and Kelvin waves along the equatorial Atlantic. The propagation of Kelvin and Rossby waves are highlighted with white and pinks arrows, for downwelling and upwelling conditions respectively. 
(a) SST-WIND AUGUST MM-REF

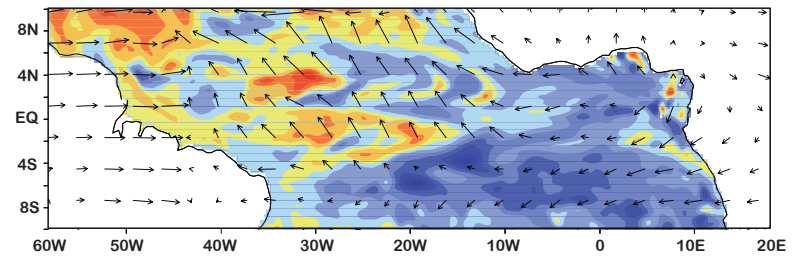

(b) SST-WIND AUGUST MM-WAVE

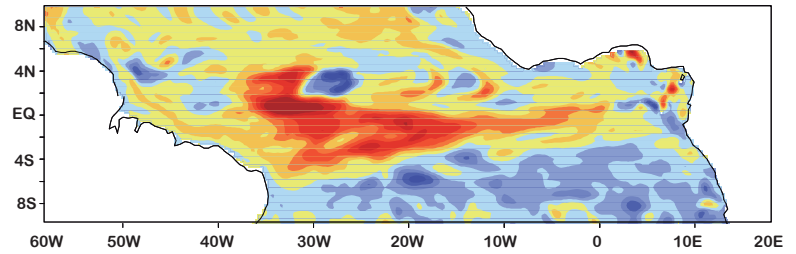

(c) SST-WIND AUGUST MM-WIND
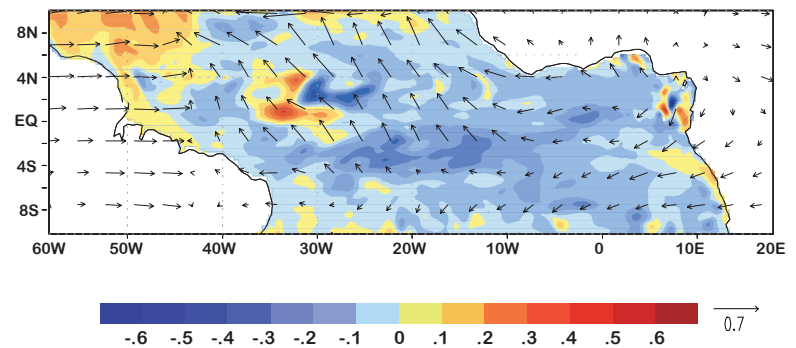

(d) SST-SSH $5 d$ anom ATL3 $\left[20^{\circ} \mathrm{W}-0^{\circ}, 3^{\circ} \mathrm{N}-3^{\circ} \mathrm{S}\right]$

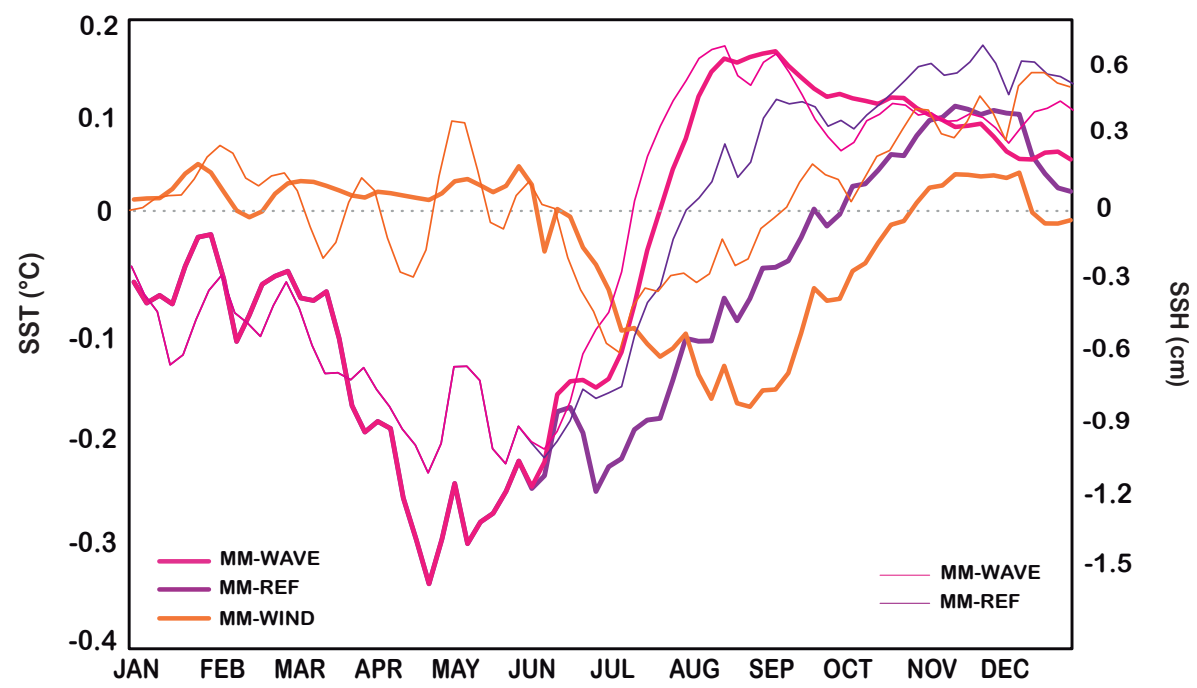

Figure 5. Impact of the wave activity in the equatorial Atlantic variability. (a-c) Anomalous SST(shaded, in ${ }^{\circ} \mathrm{C}$ ) and surface wind forcing (vector, in $\mathrm{m} / \mathrm{s}$ ) in the equatorial Atlantic in August for MM-REF, MM-WAVE and MM-WIND. (d-e) Time series of anomalous 5-day SST (solid thick lines, in ${ }^{\circ} \mathrm{C}$ ) and SSH (solid thin lines, in $\mathrm{cm}$ ) in the Atl3 region for MM-REF, MM-WAVE and MM-WIND from January to December. 
(a) HB terms $5 d$ anom ATL3 $\left[20^{\circ} \mathrm{W}-0^{\circ}, 3^{\circ} \mathrm{N}-3^{\circ} \mathrm{S}\right] \mathrm{MM}-\mathrm{REF}$

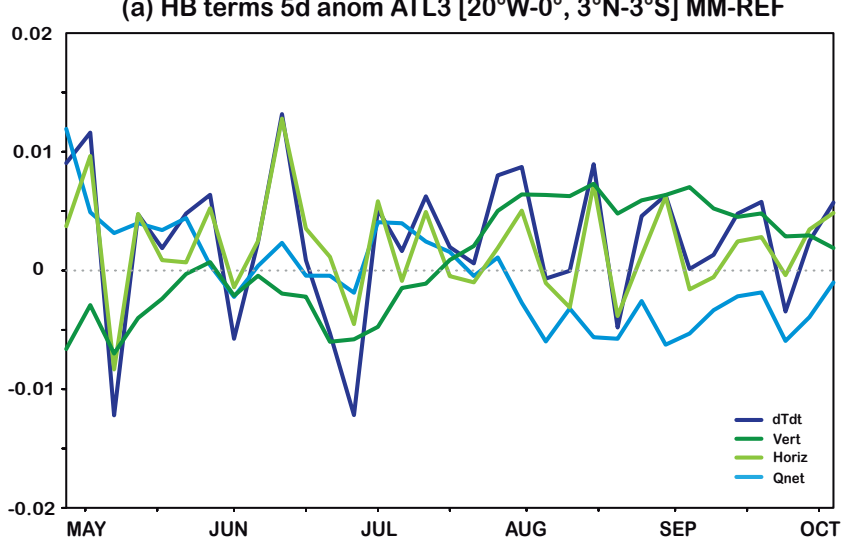

(b) HB terms $5 \mathrm{~d}$ anom ATL3 $\left[20^{\circ} \mathrm{W}-0^{\circ}, 3^{\circ} \mathrm{N}-3^{\circ} \mathrm{S}\right] \mathrm{MM}-\mathrm{WAVE}$

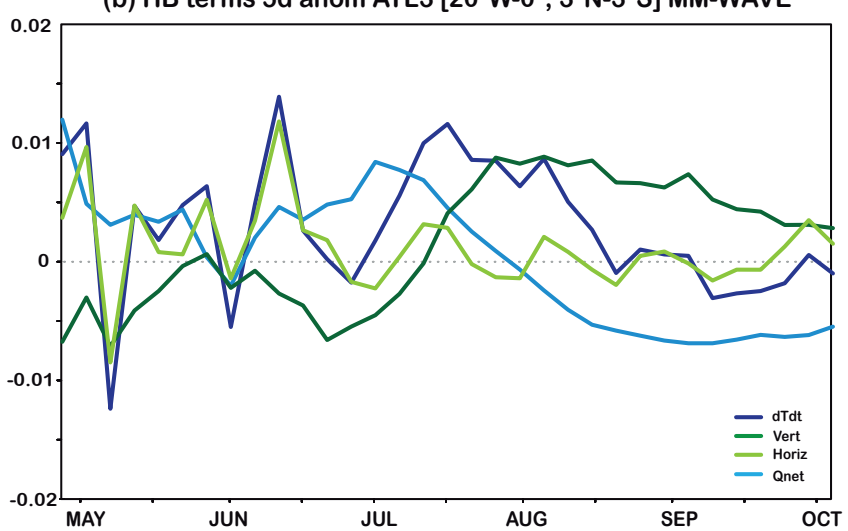

(c) HB terms $5 d$ anom ATL3 $\left[20^{\circ} \mathrm{W}-0^{\circ}, 3^{\circ} \mathrm{N}-3^{\circ} \mathrm{S}\right] \mathrm{MM}-\mathrm{WIND}$

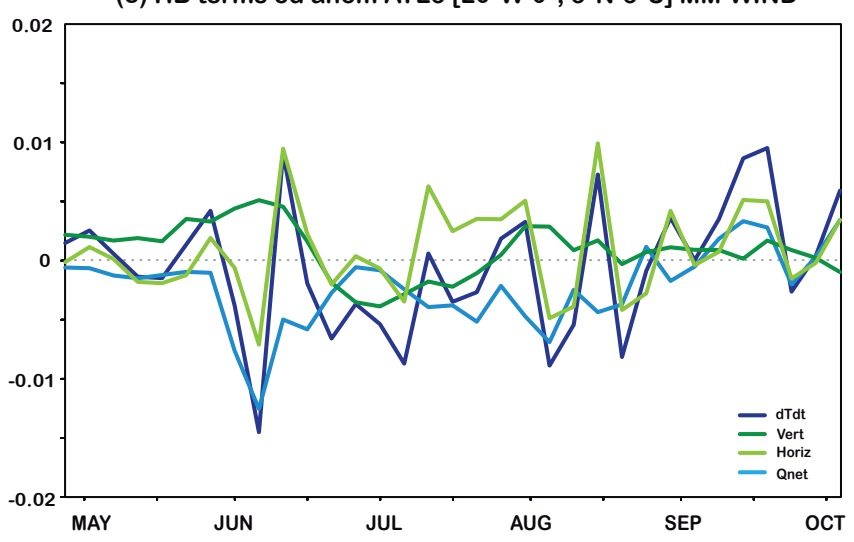

Figure 6. Heat budget analysis in the eastern equatorial Atlantic. (a-c) Anomalous 5-day heat budget terms (temperature trend, air-sea fluxes, vertical and horizontal processes, in ${ }^{\circ} \mathrm{C} /$ day) in MM-REF, MMWAVE and MM-WIND simulations from January to December. 
(a) MM-EM events OBS \& MOD 1960-2011
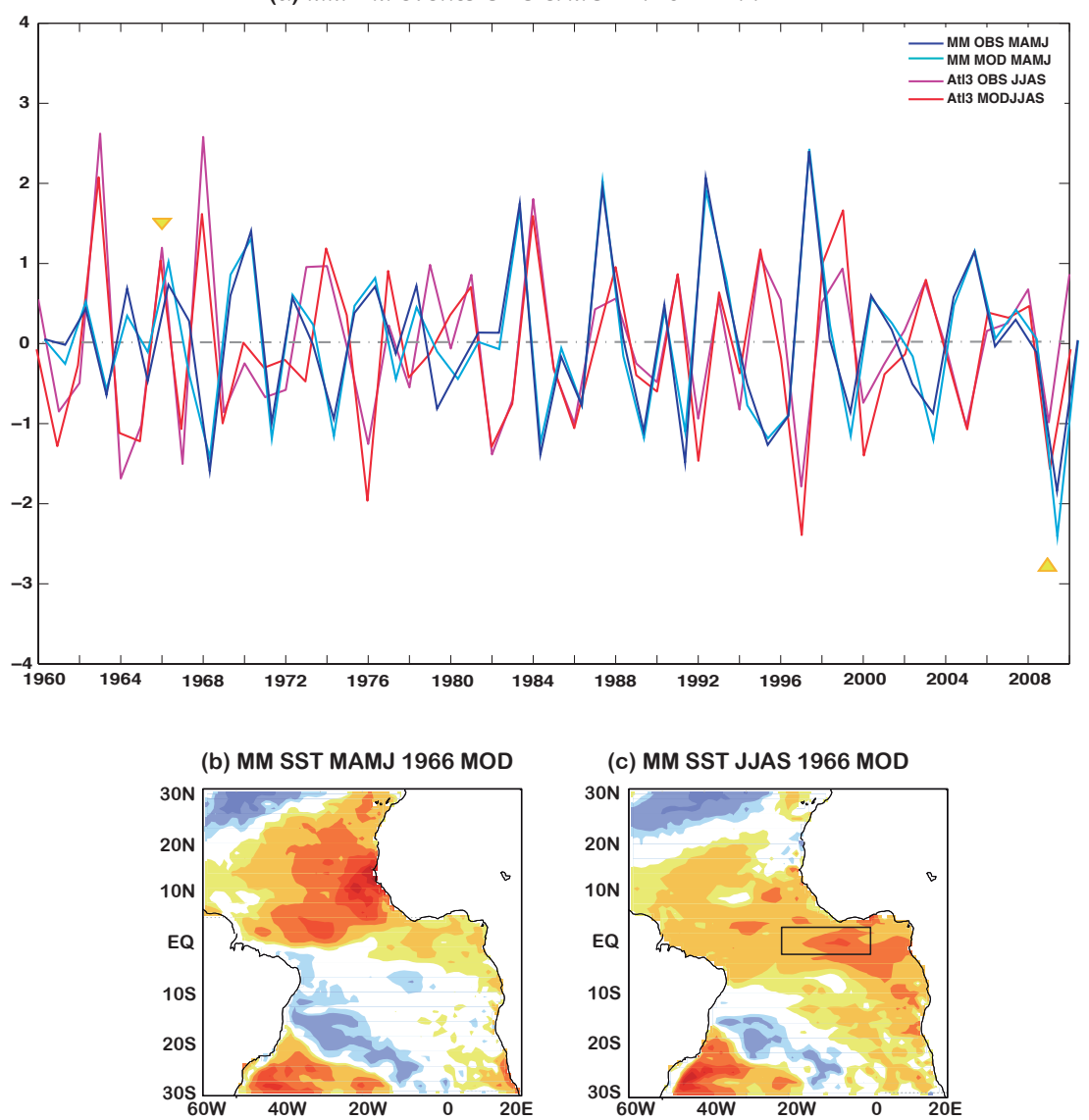

(d) MM SST MAMJ 2009 MOD

(e) MM SST JJAS 2009 MOD
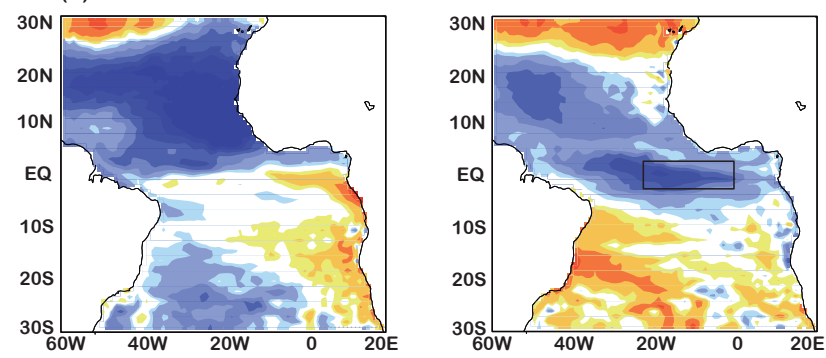

$\begin{array}{lllllllllllllllllll}-1.2 & -1 & -.8 & -.6 & -.4 & -.2 & -1 & -.05 & 05 & .1 & 2 & .4 & .6 & .8 & 1 & 1.2\end{array}$

Figure 7. Meridional Mode followed by Equatorial Mode events. (a) Time series of Meridional Mode (PC2) and Equatorial Mode (At13) during 1960-2011 for observations and INTER simulation. (b-e) Observed anomalous tropical Atlantic SSTs in boreal spring (MAMJ) and summer (JJAS) months are displayed for two Meridional Mode events, 1966 and 2009. In both cases, pronounced equatorial SST anomalies during summer months followed the development of a same-sign Meridional Mode event. 


\section{References}

Amaya, D. J., M. J. DeFlorio, A. J. Miller, and S.-P. Xie, 2016: WES feedback and the Atlantic Meridional Mode: observations and CMIP5 comparisons. Clim. Dyn, 1-15.

Andreoli, R. V., and M. T. Kayano, 2003: Evolution of the equatorial and dipole modes of the sea-surface temperature in the Tropical Atlantic at decadal scale. Meteorology and Atmospheric Physics, 83, 277-285.

Bjerknes, J., 1969: Atmospheric teleconnections from the equatorial Pacific. Mon. Wea. Rev., 97, 163-172.

Brandt, P., A. Funk, V. Hormann, M. Dengler, R. J. Greatbatch, and J. M. Toole, 2011: Interannual atmospheric variability forced by the deep equatorial Atlantic Ocean. Nature, 473, 497.

Brodeau, L., B. Barnier, A. M. Treguier, T. Penduff, and S. Gulev, 2010: An ERA40based atmospheric forcing for global ocean circulation models. Ocea. Mod., 31, 88-104.

Burmeister, K., P. Brandt, and J. Lübbecke, 2016: Revisiting the cause of the eastern equatorial Atlantic cold event in 2009. J. Geophys. Res.: Oceans, 121, 4777-4789.

Butterworth, S., 1930: On the theory of filter amplifiers. Experimental wireless and the wireless engineer 7, 536-541.

Carton, J. A., and B. Huang, 1994: Warm Events in the Tropical Atlantic. J. Phys. Ocea., 24, 888-903.

Czaja, A., P. Van der Vaart, and J. Marshall, 2002: A Diagnostic Study of the Role of Remote Forcing in Tropical Atlantic Variability. J. Climate, 15, 3280-3290.

Faye, S., A. Lazar, B. Sow, and A. Gaye, 2015: A model study of the seasonality of sea surface temperature and circulation in the Atlantic North-eastern Tropical Upwelling System. FrPhy, 3, 76.

Foltz, G. R., and M. J. McPhaden, 2010a: Interaction between the Atlantic meridional and Niño modes. Geophys. Res. Lett., 37, L18604.

- 2010b: Abrupt equatorial wave-induced cooling of the Atlantic cold tongue in 2009. Geophys. Res. Lett., 37, n/a-n/a.

Foltz, G. R., S. A. Grodsky, J. A. Carton, and M. J. McPhaden, 2003: Seasonal mixed layer heat budget of the tropical Atlantic Ocean. J. Geophys. Res.: Oceans, 108, 3146.

Handoh, I. C., G. R. Bigg, A. J. Matthews, and D. P. Stevens, 2006: Interannual variability of the Tropical Atlantic independent of and associated with ENSO: Part II. The South Tropical Atlantic. International Journal of Climatology, 26, 1957-1976. 
Huang, B., and J. Shukla, 1997: Characteristics of the Interannual and Decadal Variability in a General Circulation Model of the Tropical Atlantic Ocean. J. Phys. Ocea., 27, 16931712 .

Illig, S., and Coauthors, 2004: Interannual long equatorial waves in the tropical Atlantic from a high-resolution ocean general circulation model experiment in 1981-2000. $J$. Geophys. Res.: Oceans, 109, n/a-n/a.

Jin, D., and L. Huo, 2018: Influence of tropical Atlantic sea surface temperature anomalies on the East Asian summer monsoon. Q.J.R. Met. Soc., 144, 1490-1500.

Jouanno, J., O. Hernandez, and E. Sanchez-Gomez, 2017: Equatorial Atlantic interannual variability and its relation to dynamic and thermodynamic processes. Earth Systems Dynamics, 8, 1061-1069.

Keenlyside, N. S., and M. Latif, 2007: Understanding Equatorial Atlantic Interannual Variability. J. Climate, 20, 131-142.

Kucharski, F., A. Bracco, J. H. Yoo, and F. Molteni, 2008: Atlantic forced component of the Indian monsoon interannual variability. Geophys. Res. Lett., 35, L04706.

Kucharski, F., A. Bracco, J. H. Yoo, A. M. Tompkins, L. Feudale, P. Ruti, and A. Dell'Aquila, 2009: A Gill-Matsuno-type mechanism explains the tropical Atlantic influence on African and Indian monsoon rainfall. Q.J.R. Met. Soc., 135, 569-579.

Latif, M., and A. Grötzner, 2000: The equatorial Atlantic oscillation and its response to ENSO. Clim. Dyn, 16, 213-218.

Losada, T., B. Rodríguez-Fonseca, and F. Kucharski, 2012b: Tropical influence on the summer Mediterranean climate. AtScL, 13, 36-42.

Losada, T., B. Rodriguez-Fonseca, E. Mohino, J. Bader, S. Janicot, and C. R. Mechoso, 2012a: Tropical SST and Sahel rainfall: A non-stationary relationship. Geophys. Res. Lett., 39, L12705.

Lübbecke, J., and M. J. McPhaden, 2012: On the Inconsistent Relationship between Pacific and Atlantic Niños*. J. Climate, 25, 4294-4303.

- 2013: A Comparative Stability Analysis of Atlantic and Pacific Niño Modes*. $J$. Climate, 26, 5965-5980.

Lübbecke, J., C. W. Böning, N. S. Keenlyside, and S.-P. Xie, 2010: On the connection between Benguela and equatorial Atlantic Niños and the role of the South Atlantic Anticyclone. J. Geophys. Res.: Oceans, 115, C09015.

Lübbecke, J., B. Rodríguez-Fonseca, I. Richter, M. Martín-Rey, T. Losada, I. Polo, and N. Keenlyside, 2018: Equatorial Atlantic variability - modes, mechanisms and global teleconnections. Wiley Interdisciplinary Reviews: Climate Change.

Madec, G., 2008: NEMO ocean engine, Note du Pole de modèlisation. 
Martín-Rey, M., B. Rodríguez-Fonseca, and I. Polo, 2015: Atlantic opportunities for ENSO prediction. Geophys. Res. Lett., 42, 6802-6810.

Martín-Rey, M., B. Rodríguez-Fonseca, I. Polo, and F. Kucharski, 2014: On the AtlanticPacific Niños connection: a multidecadal modulated mode. Clim. Dyn, 43, 3163-3178.

Martín-Rey, M., I. Polo, B. Rodríguez-Fonseca, A. Lazar, and T. Losada, 2019: Ocean dynamics shapes the structure and timing of tropical Atlantic variability modes Geophys. Res. Lett., submitted.

Mohino, E., and T. Losada, 2015: Impacts of the Atlantic Equatorial Mode in a warmer climate. Clim. Dyn, 45, 2255-2271.

Murtugudde, R. G., J. Ballabrera-Poy, J. Beauchamp, and A. J. Busalacchi, 2001: Relationship between zonal and meridional modes in the tropical Atlantic. Geophys. Res. Lett., 28, 4463-4466.

Nnamchi, H., J. Li, F. Kucharski, I.-S. Kang, N. S. Keenlyside, P. Chang, and R. Farneti, 2015: Thermodynamic controls of the Atlantic Niño. Nature Communications, 6, 8895.

- 2016: An Equatorial-Extratropical Dipole Structure of the Atlantic Niño. $J$. Climate, 29, 7295-7311.

Nobre, P., and J. Shukla, 1996: Variations in sea surface temperatura, wind stress, and rainfall over the tropical Atlantic and South America. J. Climate, 9, 2464-2479.

Peter, A.-C., and Coauthors, 2006: A model study of the seasonal mixed layer heat budget in the equatorial Atlantic. J. Geophys. Res.: Oceans, 111, C06014.

Polo, I., B. Rodríguez-Fonseca, T. Losada, and J. García-Serrano, 2008a: Tropical Atlantic Variability Modes (1979-2002). Part I: Time-Evolving SST Modes Related to West African Rainfall. J. Climate, 21, 6457-6475.

Polo, I., A. Lazar, B. Rodriguez-Fonseca, and S. Arnault, 2008b: Oceanic Kelvin waves and tropical Atlantic intraseasonal variability: 1. Kelvin wave characterization. $J$. Geophys. Res.: Oceans, 113, C07009.

Polo, I., A. Lazar, B. Rodriguez-Fonseca, and J. Mignot, 2015a: Growth and decay of the equatorial Atlantic SST mode by means of closed heat budget in a coupled general circulation model. Frontiers in Earth Science, 3, 37.

Polo, I., M. Martín-Rey, B. Rodriguez-Fonseca, F. Kucharski, and C. Mechoso, 2015b: Processes in the Pacific La Niña onset triggered by the Atlantic Niño. Clim. Dyn, 44, 115131.

Rayner, N. A., and Coauthors, 2003: Global analyses of sea surface temperature, sea ice, and night marine air temperature since the late nineteenth century. J. Geophys. Res.:Atmosphere, 108, 4407. 
Richter, I., S. K. Behera, Y. Masumoto, B. Taguchi, H. Sasaki, and T. Yamagata, 2013: Multiple causes of interannual sea surface temperature variability in the equatorial Atlantic Ocean. Nature Geoscience, 6, 43-47.

Rodríguez-Fonseca, B., I. Polo, J. García-Serrano, T. Losada, E. Mohino, C. R. Mechoso, and F. Kucharski, 2009: Are Atlantic Niños enhancing Pacific ENSO events in recent decades? Geophys. Res. Lett., 36, L20705.

Rodríguez-Fonseca, B., and Coauthors, 2015: Variability and Predictability of West African Droughts: A Review on the Role of Sea Surface Temperature Anomalies. $J$. Climate, 28, 4034-4060.

Ruiz-Barradas, A., J. A. Carton, and S. Nigam, 2000: Structure of Interannual-to-Decadal Climate Variability in the Tropical Atlantic Sector. J. Climate, 13, 3285-3297.

Servain, J., I. Wainer, J. P. McCreary, and A. Dessier, 1999: Relationship between the equatorial and meridional modes of climatic variability in the tropical Atlantic. Geophys. Res. Lett., 26, 485-488.

Suarez, M. J., and P. S. Schopf, 1988: A Delayed Action Oscillator for ENSO. J. Atmos. Sci., 45, 3283-3287.

von Storch, H., and F. Zwiers, 2001: Statistical Analysis in Climate Research. Cambridge University Press, 484

Zebiak, S. E., 1993: Air-Sea Interaction in the Equatorial Atlantic Region. J. Climate, 6, 1567-1586.

Zhu, J., B. Huang, and Z. Wu, 2012: The Role of Ocean Dynamics in the Interaction between the Atlantic Meridional and Equatorial Modes. J. Climate, 25, 3583-3598. 